\title{
Aspirin-sensitive rhinitis-associated changes in upper airway innervation
}

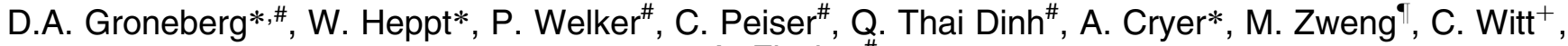 \\ A. Fischer"
}

Aspirin-sensitive rhinitis-associated changes in upper airway innervation. D.A. Groneberg, W. Heppt, P. Welker, C. Peiser, Q. Thai Dinh, A. Cryer, M. Zweng, C. Witt, A. Fischer. (C) ERS Journals Ltd 2003.

ABSTRACT: Aspirin-sensitive rhinitis is the manifestation of aspirin intolerance in the upper respiratory tract. The disease represents a pseudoallergy against aspirin or related nonsteroidal anti-inflammatory drugs. As a major immunomodulatory role for airway innervation has been proposed in airway inflammatory diseases, the present study assessed changes in human nasal mucosa innervation in patients with aspirinsensitive rhinitis in comparison to a control group.

Immunohistochemistry for protein gene product 9.5, tachykinins, calcitonin generelated peptide, vasoactive intestinal peptide (VIP) and neuropeptide tyrosine was performed on cryostats sections of nasal mucosa and neuropeptide containing nerves were examined independently using a score grading.

In comparison to the control, the aspirin-sensitive rhinitis group had a significant increase of VIP-like immunoreactivity in mucosal nerve fibres. In contrast to constant numbers of mast cells, highly significant increases in the numbers of eosinophils were found in the group of aspirin-sensitive rhinitis patients.

In summary, the present quantification of neuropeptide-immunoreactivity of mucosal nerves demonstrated differences in the human nasal mucosa innervation between nonrhinitic and aspirin-sensitive rhinitic individuals. These differences may reflect a pathophysiological role of upper airway innervation in pseudoallergic reactions.

Eur Respir J 2003; 22: 986-991.
*Dept of Otorhinolaryngology, Karlsruhe Teaching Hospital, University of Freiburg, Karlsruhe, " Division of Allergy Research, Dept of Pediatric Pneumology and Immunology, Charité, Humboldt-University, Berlin, Dept of Otorhinolaryngology, School of Medicine, University of Hannover, Hannover, ${ }^{+}$Dept of Medicine, Charité Campus Mitte, Humboldt-University, Berlin, Germany.

Correspondence: A. Fischer, Division of Allergy Research, Dept of Pediatric Pneumology and Immunology, Charité Campus Virchow, Biomedical Research Center OR-3, Augustenburger Platz 1, D-13353 Berlin, Germany.

Fax: 4930450559951

E-mail: axel.fischer@charite.de

Keywords: Aspirin, neuropeptides, rhinitis

Received: September 172002

Accepted after revision: June 222003

This study was supported by German Research Community and Federal Ministry for Education and Research (01 GC 0002) grants.
Aspirin (acetylsalicylic acid) is still one of the most frequently used drugs of all times. In addition to its role as an analgetic drug, aspirin is also increasingly used in the prophylaxis of vascular diseases. The prevalence of aspirin intolerance varies from 5-6\% [1] and an association of nasal polyposis, asthma and sensitivity towards aspirin has been known for $\sim 80$ yrs [2]. The association of asthma, nasal polyposis and aspirin sensitivity is known as the aspirin triad [3].

Aspirin-induced asthma (AIA) represents the development of a severe drop in forced expiratory volume in one second (FEV1) in patients following the administration of aspirin. In patients with AIA, acute symptoms are often superimposed on chronic severe asthma. The attacks may be precipitated following the ingestion of small amounts of aspirin or other nonsteroidal anti-inflammatory drugs (NSAID)s. HEDMAN et al. [4] showed an overall aspirin intolerance of 5.7\% and the prevalence of AIA to be $1.2 \%$. Over the last few years, there has been an increased understanding of the pathogenesis and management of AIA. Aspirin-induced bronchoconstriction is thought to be caused by the shunting of the arachidonic acid metabolism away from the cyclooxygenase pathway toward the lipoxygenase pathway. This results in an increased production of leukotrienes (LT)s with resultant bronchoconstriction [2]. Consistent with this finding, a severe drop in FEV1 in patients with AIA can be inhibited by LT receptor antagonists [5] and an abnormal release of LTs is found in aspirinsensitive asthmatic patients, which contributes to nasal and bronchial adverse reactions [6].

It is known that rhinosinusitis in aspirin-sensitive asthmatic patients is more severe than in aspirin-tolerant patients [7]. Also, the extent and severity of the mucosal inflammation has been suggested to be higher in aspirin-sensitive patients than that in aspirin-tolerant patients. Using computed tomographic scanning to assess the extent of sinus involvement and measurement of mucosal thickening in the paranasal sinuses, a semiquantitative scoring system was developed and revealed that the extent of hyperplastic rhinosinusitis is greater in aspirin sensitive than in aspirin-tolerant asthmatic subjects with rhinosinusitis of similar clinical severity [3].

It is not clear if the basic mechanism of chronic airway inflammation in aspirin-sensitive patients is different from that in aspirin-tolerant patients with chronic rhinosinusitis and nasal polyps. As the autonomic airway nervous system has been reported to play a major role in the development of inflammatory airways diseases of the upper and lower respiratory tract $[8,9]$, it was presently hypothesised that aspirin-sensitive patients have an altered pattern of neuropeptide-immunoreactive nerve fibres in their nasal mucosa if compared to subjects with no rhinitis. Therefore, the present project investigated the 
composition of neuropeptide-containing nasal mucosal nerves in a group of aspirin-sensitive rhinitis patients and nonrhinitic individuals and assessed numbers of eosinophils and mast cells.

\section{Materials and methods}

\section{Subjects}

After approval by the ethics committee and informed consent from each individual, a total of 24 male and female individuals ( 12 with aspirin sensitivity and 12 controls) were included in the present study (table 1). For the identification of aspirin-sensitive rhinitis, a positive medical history for aspirin-sensitivity and positive reaction to a nasal provocation was obligatory, which was performed with the previously described specific lysine-aspirin provocation test [10]. All patients $(n=12)$ included to the aspirin-sensitivity group also had a history of aspirin-sensitive mild asthma and nasal polyposis next to the rhinitis. The patients did not exhibit any signs of atopic dermatitis or other types of allergies as revealed by medical history and serum immunoglobulin $\mathrm{E}$ (IgE) measurement by radio immunosorbens. The patients received nasal decongestants but all nasal or oral steroids and nasal cromoglycate were withdrawn 2 weeks prior to surgery.

To exclude other rhinitis types, skin-prick test, nasal examination, rhinomanometric test, nasal smear, and saccharin tests and nasal provocation or serum $\operatorname{IgE}$ counts by radio immunosorbens assay were performed. These tests were also performed with the controls to rule out aspirin sensitivity, allergic rhinitis, vasomotoric rhinitis or toxic rhinitis.

\section{Tissue sampling}

Surgical biopsies of the lower nasal conchae were obtained during rhinosurgical interventions due to airflow limitations with causes such as deviation of the septum or conchal hyperplasia in the control group. Also, in the control group, a normal cytology and histology was obligate to rule out possible interfering inflammatory processes, such as bacterial or viral inflammation, whereas in the aspirin-sensitive rhinitis

Table 1. - Patient characteristics

\begin{tabular}{lccccc}
\hline Patient collective & Total & $\begin{array}{c}\text { Male/ } \\
\text { female }\end{array}$ & $\begin{array}{c}\text { Age } \\
\text { yrs }\end{array}$ & Allergies & Smokers \\
\hline Reference collective & 12 & $6 / 6$ & $17-66$ & 0 & 0 \\
Aspirin-sensitive rhinitis & 12 & $5 / 7$ & $13-72$ & 0 & 0 \\
\hline
\end{tabular}

Data are presented as $n$. group, inflammatory changes were found, as described previously $[3,7,11]$. The biopsies were then processed to cryostat sections using a routine protocol [12]. Immersionfixation in Zamboni-solution [13] for $4 \mathrm{~h}$ was followed by washing the tissues in phosphate-buffered solution (PBS). Cryoprotection with $18 \%$ saccharose (1604; Riedel-de Haen AG, Seelze, Germany) was performed overnight before the biopsies were frozen in liquid nitrogen-cooled isopentane. After storage at $-80^{\circ} \mathrm{C}$ the tissues were cut to $8-10 \mu \mathrm{m}$ sections using a cryostat.

\section{Eosinophil and mast cell quantification}

Histomorphological examination of tissue sections was performed using haematoxylin-eosin staining [14]. Differentiation of mast cells and eosinophils was carried out using either conventional histochemistry or immunohistochemistry. Histochemically, mast cells and eosinophils were detected with Toluidine or Giemsa staining. For immunohistochemical detection of the two cell types, specific markers were employed. For eosinophil detection, the sections were subjected to incubation with antibodies against human eosinophil cationic protein (clone EG1 or EG2). For mast cell staining, antihuman mast cell tryptase and anti-IgE antibodies were employed (table 2). For the detection of the primary antibody reaction, biotinylated secondary antibodies and streptavidin-bioton-peroxydase complex were used. Unspecific reactions caused by endogenous tissue peroxidase were excluded by blocking with $0.5 \% \mathrm{H}_{2} \mathrm{O}_{2}$-methanol. Negative controls included omitting of primary or secondary antibodies. For quantification, randomised sections were examined by two independent investigators using a 250-fold magnification and a grating (035025, Olympus optical, Hamburg, Germany). The number of marker-positive cells was counted per 1,000 lamina propria associated nucleated, nonorgan related cells. The normal distribution was confirmed by the Kolmogorov-Smirnov test and the groups were tested for significant differences $(p<0.05)$ using a paired t-test. The results were verified using the Bonferroni-Holm procedure, which confirmed significant differences.

\section{Immunohistochemistry for neuropeptides}

Immunohistochemistry was carried out as described elsewhere [15], using a modified immunohistochemical method [16]. In brief, $8 \mu \mathrm{m}$ cryostat sections were mounted onto chromalaun precoated glass slides, air dried for $1 \mathrm{~h}$ and washed several times in PBS. To exclude unspecific background labeling, the slides were then preincubated for $1 \mathrm{~h}$ at room temperature with $0.1 \mathrm{M}$ phosphate buffer (PBS) containing $1 \%$ bovine serum albumin and $10 \%$ normal swine

Table 2.-Primary antibodies

\begin{tabular}{|c|c|c|c|c|}
\hline Antibody & Dilution & Order number & Company & Host \\
\hline $\begin{array}{l}\text { Eosinophil cationic protein } \\
\text { clone EG1 }\end{array}$ & $1: 100$ & $10-9195-01$ & Kabi Pharmacia AB, Sweden & Monoclonal mouse \\
\hline $\begin{array}{l}\text { Eosinophil cationic protein } \\
\text { clone EG2 }\end{array}$ & $1: 100$ & $10-9196-01$ & Kabi Pharmacia Diagnostics AB & Monoclonal mouse \\
\hline Mast cell tryptase & $1: 1500$ & MAB 1222 & Chemicon International Inc., USA & Monoclonal mouse \\
\hline Immunoglobulin E & $1: 30$ & $010195 \mathrm{~A}$ & Bio-Science Products AG, Switzerland & Monoclonal mouse \\
\hline Protein gene-product 9.5 & $1: 800$ & RA95101 & Ultraclone, UK & Polyclonal rabbit \\
\hline Substance $\mathrm{P}$ & $1: 40$ & YMC1021 & Accurate Chemical \& Scientific Corp., USA & Polyclonal rabbit \\
\hline Calcitonin gene-related peptide & $1: 400$ & RAS6009N & Peninsula, USA & Polyclonal rabbit \\
\hline Vasoactive intestinal peptide & $1: 400$ & RAS7161N & Peninsula, USA & Polyclonal rabbit \\
\hline Neuropeptide tyrosine & $1: 400$ & CA08295 & $\mathrm{CRB}, \mathrm{UK}$ & Polyclonal rabbit \\
\hline
\end{tabular}


serum. Sections were then rinsed in PBS and subjected to overnight incubation with markers for protein gene product (PGP) 9.5 and different neuropeptides (table 2). Of these neuropeptide markers, the substance $P$ antiserum may exhibit cross-reactivity to other tachykinins (SP), such as neurokinin A. For the detection of the primary antibodies, different secondary antibodies were employed (table 3 ). For controls, incubations were performed without the addition of the primary or secondary antibodies. The sections were finally mounted in carbonate-buffered glycerol $(\mathrm{pH} 8.6)$ and examined with fluorescence microscopy. For semi-quantitative evaluation of the neuropeptide-immunoreactivity, two independent investigators scored the staining intensity using a 90 -fold magnification and a previously established scoring system. The innervation density was graded in steps from $0-4$. Grade 0 represents no detectable staining, grade 1 represents occasional (focal) staining, grade 2 represents few nerve fibre profiles (diffuse weak) detectable, grade 3 represents many nerve fibre profiles, and grade 4, densely innervated mucosa. Similar staining protocols were published previously [17]. Samples from both groups were examined on the same day to exclude day-to-day variability influencing intergroup differences.

\section{Results}

\section{Distribution of inflammatory cells}

Routine histology demonstrated inflammatory changes in the aspirin-sensitive rhinitis group in comparison to the control group. Apart from inflammatory cell influx with a high degree of eosinophilia, goblet cell hyperplasia was also found. Giemsa-staining demonstrated that eosinophils were predominantly present in the subepithelial layer, around glands and around small blood vessels. Immunohistochemistry with the eosinophil-specific EG1 and EG2 antibodies confirmed the results of Giemsa-staining.

Toluidine-staining demonstrated the presence of mast cells. They were also predominantly present around glands and small blood vessels and in the subepithelial layer. Tryptase/ IgE-immunohistochemistry on serial sections led to a similar result (fig. 1). Both the eosinophils and mast cells were not only localised around vessels, indicating a recent diapedesis, but also found in the superficial and deeper layers of the biopsies.

\section{Quantification of mast cell and eosinophil numbers}

Quantitative histochemistry using Toluidine and Giemsa and immunohistochemistry with different mast cell and eosinophil-specific markers was employed to assess changes in the cellular influx in aspirin-sensitive rhinitis in comparison to the control group. In the aspirin-sensitive rhinitis group, highly significant differences of the eosinophil count were found, with a value of $18.7 \pm 4.9 \%$ (control group: $2.6 \pm 1.3 \%$, $\mathrm{p}<0.001)$ after EG1-staining. EG2-staining $(21.1 \pm 6.9 \%$, control

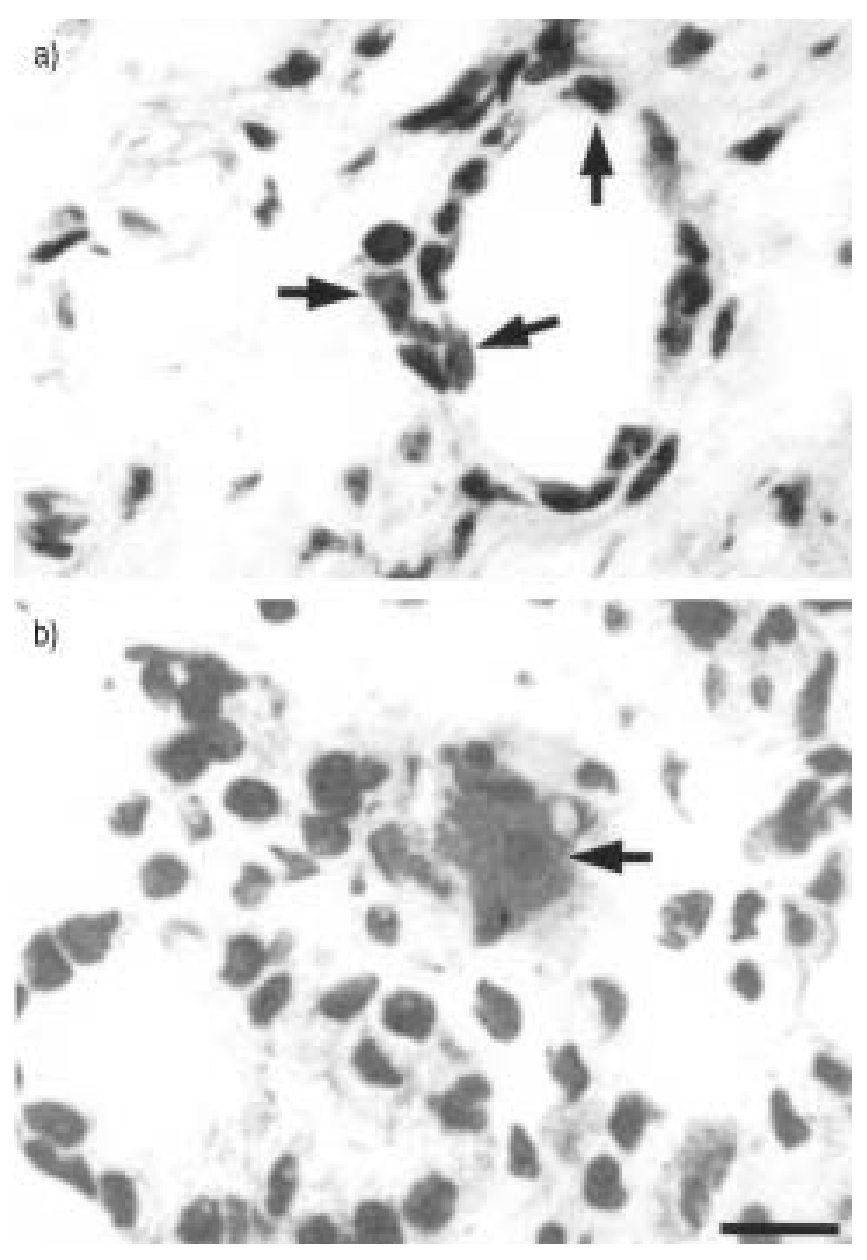

Fig. 1.- Mast cell and eosinophil distribution showing an abundant presence of eosinophils in the mucosa around small blood vessels. Arrows show mast cells. Internal scale bar $=40 \mu \mathrm{m}$.

group: $2.7 \pm 1.2 \%, \mathrm{p}<0.001)$ confirmed this finding. The mast cells were not significantly increased in the aspirin-sensitive group when compared to the control group (toluidin: $6.6 \pm 0.9 \%$ versus $6.5 \pm 0.7 \%, \mathrm{p}=0.921$; tryptase: $6.8 \pm 1.0 \%$ versus $7.9 \pm 1.0 \%$, $\mathrm{p}=0.309$ ).

\section{Cellular expression of neuropeptides}

Biopsies of turbinate mucosa from nonrhinitic and aspirinsensitive rhinitic patients contained abundant nerve fibres. Immunohistochemistry using the general neuronal marker PGP 9.5 resulted in staining of mucosal nerve fibres. A dense innervation was found underneath the respiratory epithelium. PGP 9.5-like immunoreactivity was also found within glandular structures underneath the surface epithelium. Immunohistochemistry using a neuropeptide tyrosine (NPY)-antibody lead to staining of nerve fibres that were predominantly

Table 3.-Secondary reagents

\begin{tabular}{lccc}
\hline Antibody & Dilution & Order number & Company \\
\hline Anti-rabbit IgG, FITC-conjugated & $1: 25$ & $4271-1$ & Target \\
Anti-rabbit IgG, biotin-conjugated & $1: 50$ & 1004 & Amersham, UK Israel \\
Anti-streptavidin texas-red & $1: 50$ & RPN1233 & Amersham, UK \\
\hline
\end{tabular}

IgG: immunoglobulin G. 
distributed around blood vessels. Incubations of sections for calcitonin gene-related peptide (CGRP)-like immunoreactivity resulted in staining of CGRP-like positive fibres that were predominantly distributed close to blood vessels, glands and sinusoids. Also, tachykinin-like immunoreactivity was found in a subpopulation of nerve fibres that was present below the epithelium and around glandular structures. Immunostaining for the neuropeptide vasoactive intestinal peptide (VIP) revealed a subpopulation of VIP-like positive nerve fibres that was found around blood vessels and submucosal glands (fig. 2). Next to their expression in nerve fibres, neuroendocrine cells also revealed neuropeptide-like immunoreactivity.

\section{Quantification of neuropeptide-containing nerve fibres}

Using a previously standardised scoring protocol for nerve fibre presence in human nasal mucosa, different scores for neuropeptide-like immunoreactivity were found (fig. 3). In the control group of nonrhinitis subjects, the score was SP $1.83 \pm 0.39$, CGRP $1.58 \pm 0.36$, VIP $1.42 \pm 0.45$, and NPY $0.83 \pm 0.34$, respectively (fig. 4 ).

In the group of aspirin-sensitive rhinitis the neuropeptidelike immunoreactivity was significantly raised for VIP $(2.50 \pm 0.26, \mathrm{p}<0.05)$, whereas the other values did not differ

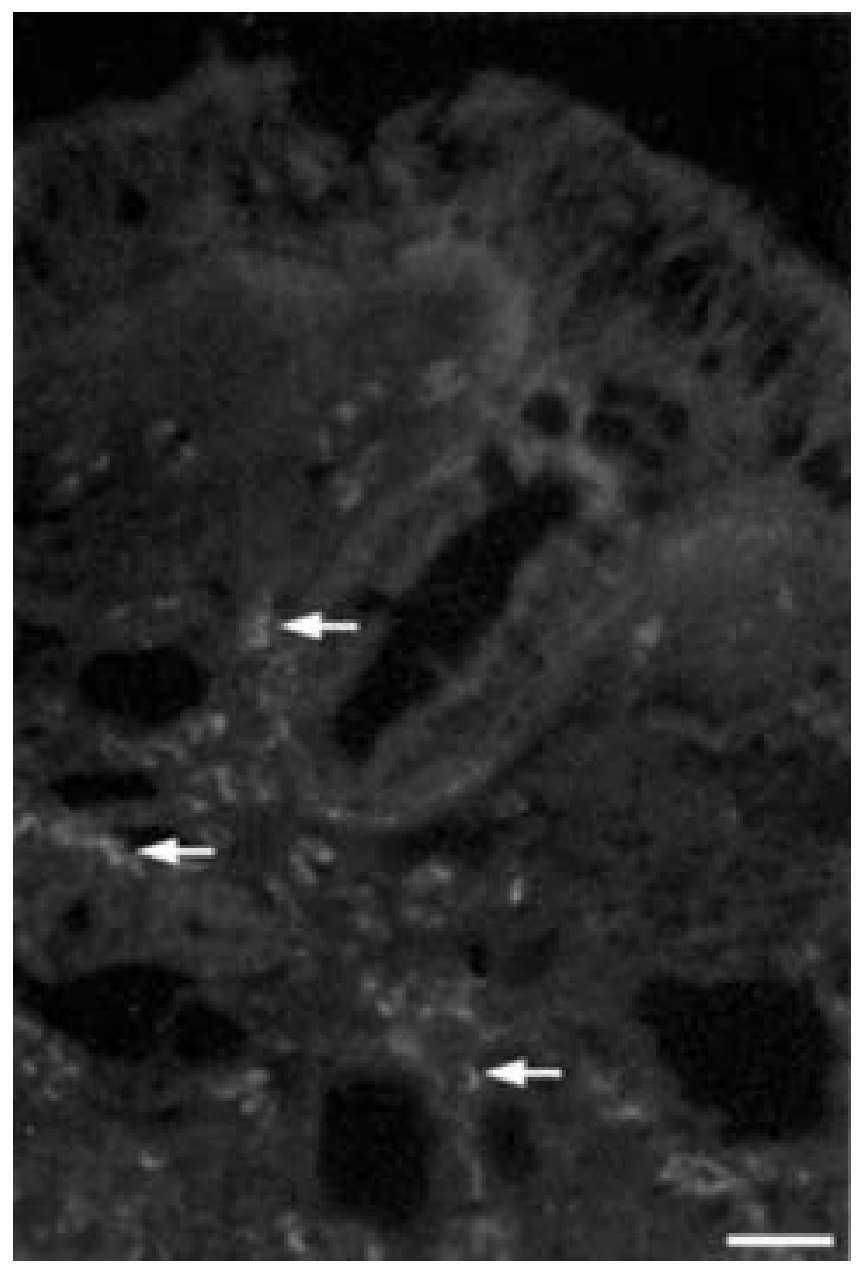

Fig. 2.-Immunohistochemistry for neuropeptides in nasal mucosal nerves. Vasoactive intestinal peptide-immunoreactive nerve fibres (arrows) are present as branching networks in the subepithelial and epithelial layer around submucosal glands and vessels in a rhinitis biopsy. Internal scale bar $=40 \mu \mathrm{m}$.

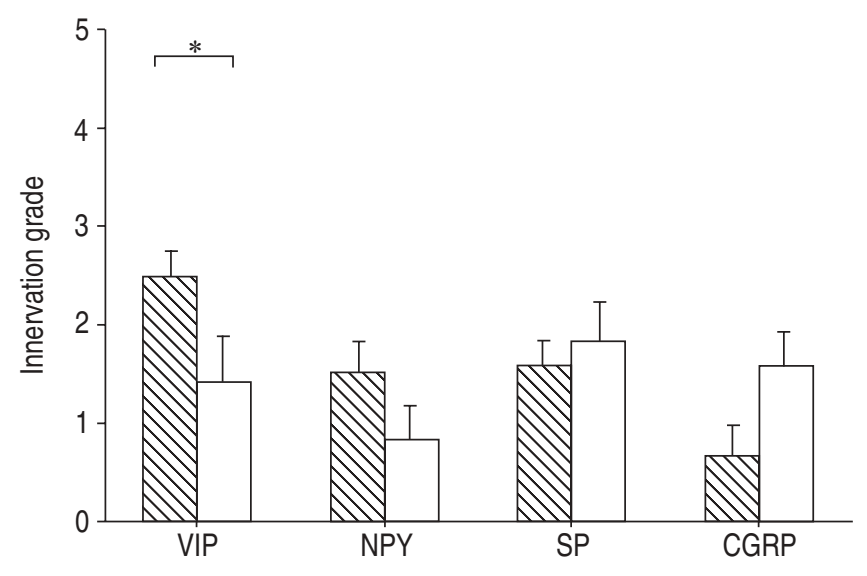

Fig. 3.-Semiquantitative assessment of neuropeptide immunoreactivity in nerve fibres in aspirin-sensitive rhinitis $(\mathbb{\mathbb { N }})$ and control tissues ( $\square)$. VIP: vasoactive intestinal peptide; NPY: neuropeptide tyrosine; SP: tachykinins; CGRP: calcitonin gene-related peptide. * $*$ p $<0.05$.

significantly (CGRP: $0.67 \pm 0.31, \mathrm{p}=0.066$; SP: $1.58 \pm 0.26$, $\mathrm{p}=0.596$; NPY: $1.50 \pm 0.31$, $\mathrm{p}=0.167$; fig. 3 ). Also, the immunoreactivity for PGP 9.5 did not change significantly (rhinitis: $2.91 \pm 0.21$ versus control: $2.30 \pm 0.56, \mathrm{p}=0.303$ ).

\section{Discussion}

Aspirin-sensitive rhinitis displays the nasal manifestation of aspirin-intolerance, a pseudoallergy against aspirin and/or related NSAIDs, such as indomethacin, diclofenac or ibuprofen [18]. Clinically, aspirin-sensitive rhinitis is often associated to hyperplastic rhinosinusitis with clear secretion, nasal obstruction, sneezing and itching. Rhinoscopy often reveals a swelling of the turbinal mucosa, a massive yellow secretion that can be due to a high content of eosinophils, and a polyposis nasi [11]. Similar features were also found in the present population of aspirin-sensitive rhinitis patients. The present cases were diagnosed according to the generally accepted diagnosis criteria including nasal provocation tests with aspirin [19, 20]. All subjects included to the study had negative radioallergosorbent test and skin tests. As most asthmatics have atopy and positive test results, the present results can clearly not be generalised to atopic asthmatics or atopic rhinitis.

The pathomechanisms of aspirin-sensitive rhinitis have not been fully elucidated so far. One theory proposes that aspirin leads directly to an unspecific, IgE-independent activation of mast cells and eosinophils [21-23]. Studies that reported an increase in the blood levels of histamine and tryptase [24], and an increase of histamine and leukotriene $\mathrm{C} 4$ in nasal lavage [25] after aspirin-provocation supported this theory. A second theory is based on the mode of action of NSAIDs that inhibit the cyclooxygenase, leading to an increased degradation of arachidonic acid by 5-lipoxygenase and an increased production of LTs $[26,27]$ and numerous studies correspond to this theory [28-31]. Apart from these pathogenetic mechanisms, a modulatory role may be attributed to the airway nervous system.

The current study assessed changes in the innervation of 12 aspirin-sensitive rhinitis patients. Using a previously standardised scoring protocol for nerve fibre presence in human nasal mucosa, a significant increase of neuropeptide VIP-like immunoreactivity was found. With the regard to the difficulties that can be encountered in quantification and semiquantification of nerve fibre profiles, the staining procedures and microscope settings have to be very stringent and reproducible. In this respect, the present study was carried out cautiously to reach the highest standards of reproducibility and stringency. 

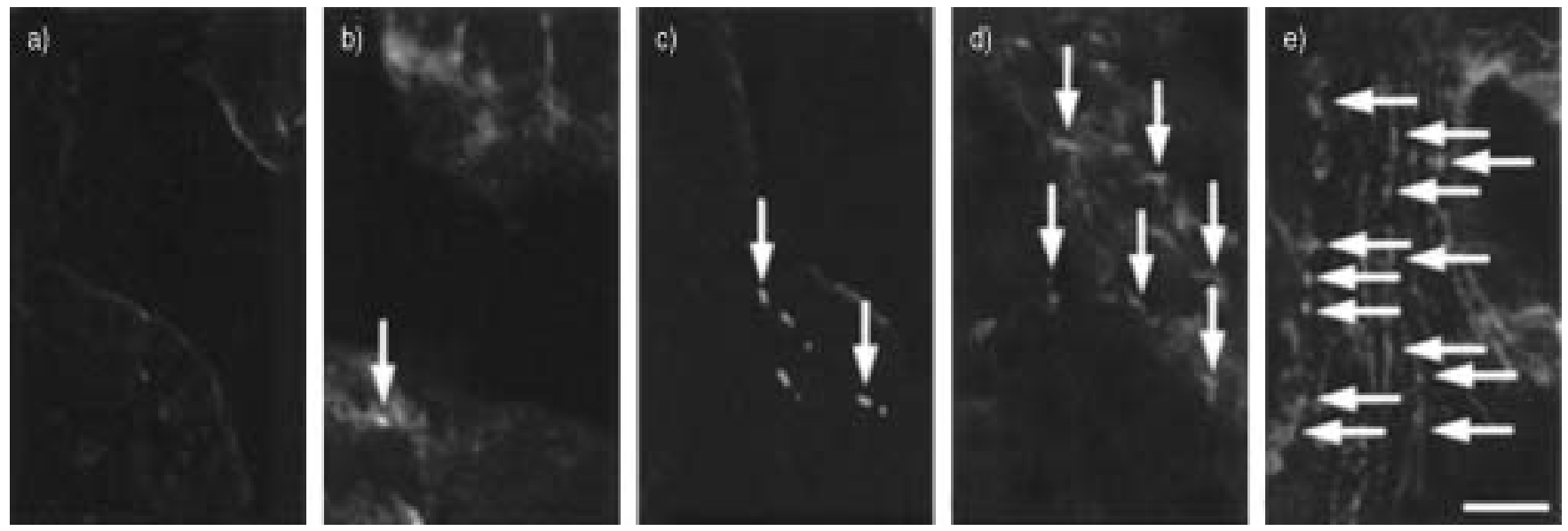

Fig. 4.-Semiquantitative assessment of neuropeptide-immunoreactivity in nerve fibres. a) Staining recorded for calcitonin gene-related peptidelike immunoreactivity in a rhinitis biopsy (grade 0). b) Arrow shows occasional (focal) staining for neuropeptide tyrosine-like immunoreactivity in a control tissue (grade 1). c) Arrows show staining for tachykinin-like immunoreactivity in a control tissue, representing few nerve fibre profiles (diffuse weak (grade 2)). d) Arrows show staining recorded for vasoactive intestinal peptide (VIP)-like immunoreactivity in a rhinitis tissue, representing many nerve fibre profiles (grade 3). e) Arrows show staining recorded for VIP-like immunoreactivity in a rhinitis tissue, representing densely innervated mucosa (grade 4). Internal scale bar $=40 \mu \mathrm{m}$.

The 28-amino acid peptide VIP was first isolated from small intestine and lung as a vasodilatory peptide [32] and is one of the most abundant neuropeptides found in human nasal mucosa [33, 34]. Although there are no reports on the effects of nasally-administered VIP in humans, it is generally accepted that VIP plays a major role in the upper respiratory tract and influences many aspects of airway function [35] due to its role as a neuromodulator of the inhibitory nonadrenergic noncholinergic nervous system [36]. An increase and upregulation of VIP expression in nerve fibres with a resulting vasodilation may be reflected by the increased blood flow and dilated vessels observed in an inflammatory setting as found in the nasal mucosa of aspirin-sensitive rhinitis patients.

VIP-like immunoreactive nerves are widely distributed throughout the respiratory tract in humans and in animals [37] and an increase of VIP has been reported in cases of vasomotor rhinitis as compared to normal controls [38, 39]. Several reports have since confirmed an up-regulation of VIP in allergic rhinitis $[17,40]$.

Next to their expression in nerve fibres, a number of studies have reported that cells of the immune system may also produce neuropeptides, such as VIP [41]. Hence, the biological significance of inflammatory cell-derived neuropeptides is discussed [42]. As the present study only focused on neuropeptide expression in nerve fibres, which can be visualised by staining with a panneuronal marker, such as PGP 9.5, an involvement of neuropeptide-derived non-neuronal sources, such as inflammatory cells, cannot be ruled out. In this respect, neuropeptide-like immunoreactivity was also found in neuroendocrine cells as reported earlier for allergic rhinitis [40, 43].

The authors have previously demonstrated that neuropeptidelike immunoreactivity also changes in biopsies of hyperreflectoric rhinitic subjects. In relation to the present study, these changes were not only restricted to VIP-like immunoreactivity but also to SP, indicating that there are differences in the innervation between these two rhinitis types [39].

In the present study, no significant change for was CGRP found. As there was a nonsignificant tendency, studies with higher numbers of tissues and a higher statistical power may reveal a significant difference for this neuropeptide, which was reported to be involved in the regulation of many airway functions [44]. Therefore, future multicenter studies with larger populations should be carried out and may also point to a role for CGRP in aspirin-sensitive rhinitis.
Apart from the well known combination of symptoms of aspirin-intolerance, asthma and polyposis nasi, previous studies reported elevated levels of eosinophils in aspirinsensitive rhinitis. The results of the current study using three methods to assess eosinophils are consistent with these studies demonstrating a highly significant elevation of the eosinophil concentration. In this respect, the numbers of eosinophils were up to $20 \%$ of lamina propria cells in the aspirin-sensitive group, compared to only $2 \%$ of lamina propria-associated cells in the nonrhinitic reference population.

A direct participation of mast cells has not been demonstrated in the pathogenesis of aspirin-sensitive rhinitis and the only studies suggesting a mast cell contribution reported elevated levels of tryptase and histamine in nasal fluid lavages of aspirin-sensitive rhinitis patients. There was no significant difference in the levels of mast cells in the present study. However, a direct participation of these cells cannot be ruled out as they may participate via a change of their mediator profile while their total numbers remain constant.

A large body of evidence points to a direct interaction between eosinophils and/or mast cells and airway nerves, as demonstrated earlier by numerous reports [45]. As the present study did not include double staining procedures for simultaneous mast cell/eosinophil and airway nerve detection, these findings were not repeated. However, due to the high numbers of eosinophils observed in the aspirin-sensitive group, communication between eosinophils and nerve fibres is possible.

In summary, the results of the present study indicate a change of neuropeptide-like immunoreactivity in mucosal nerves of patients with aspirin-rhinitis. Together, the present data suggest a modulatory role of the autonomous mucosal innervation in aspirin-sensitive rhinitis

Acknowledgement. The authors would like to thank B. Kloft for helpful discussions.

\section{References}

1. Szczeklik A, Stevenson DD. Aspirin-induced asthma: advances in pathogenesis and management. J Allergy Clin Immunol 1999; 104: 5-13.

2. Babu KS, Salvi SS. Aspirin and asthma. Chest 2000; 118 $1470-1476$. 
3. Kowalski ML. Rhinosinusitis and nasal polyposis in aspirin sensitive and aspirin tolerant patients: are they different? Thorax 2000; 55: 84-86.

4. Hedman J, Kaprio J, Poussa T, Nieminen MM. Prevalence of asthma, aspirin intolerance, nasal polyposis and chronic obstructive pulmonary disease in a population-based study. Int J Epidemiol 1999; 28: 717-722.

5. Christie PE, Smith CM, Lee TH. The potent and selective sulfidopeptide leukotriene antagonist, SK\&F 104353, inhibits aspirin-induced asthma. Am Rev Respir Dis 1991; 144: 957-958.

6. Picado C, Ramis I, Rosello J, Bulbena O, Plaza V, Gelpi E. Release of peptide leukotrienes into nasal secretions after local instillation of aspirin in aspirin-sensitive asthmatics. Adv Prostaglandin Thromboxane Leukot Res 1991; 21: 501-502.

7. Lumry WR, Curd JG, Zeiger RS, Pleskow WW, Stevenson DD. Aspirin-sensitive rhinosinusitis: the clinical syndrome and effects of aspirin administration. J Allergy Clin Immunol 1983; 71: 580-587.

8. Fischer A, McGregor GP, Saria A, Philippin B, Kummer W. Induction of tachykinin gene and peptide expression in guinea pig nodose primary afferent neurons by allergic airway inflammation. J Clin Invest 1996; 98: 2284-2291.

9. Undem BJ, Hunter DD, Liu M, Haak-Frendscho M, Oakragly A, Fischer A. Allergen-induced sensory neuroplasticity in airways. Int Arch Allergy Immunol 1999; 118: $150-153$

10. Milewski M, Mastalerz L, Nizankowska E, Szczeklik A. Nasal provocation test with lysine-aspirin for diagnosis of aspirin-sensitive asthma. J Allergy Clin Immunol 1998; 101: 581-586.

11. Lumry WR, Curd JG, Zeiger RS, Pleskow WW, Stevenson DD. Aspirin-sensitive rhinosinusitis: the clinical syndrome and effects of aspirin administration. J Allergy Clin Immunol 1983; 71: 580-587.

12. Fischer TC, Hartmann $\mathrm{P}$, Loser $\mathrm{C}$, et al. Abundant expression of vasoactive intestinal polypeptide receptor VPAC2 mRNA in human skin. J Invest Dermatol 2001; 117: 754-756.

13. Zamboni M. Buffered picric acid-formaldehyd: A new, rapid fixative for electron microscopy. J Cell Biol 1967; 35: 148.

14. Groneberg DA, Eynott PR, Oates T, et al. Expression of MUC5AC and MUC5B mucins in normal and cystic fibrosis lung. Respir Med 2002; 96: 81-86.

15. Groneberg DA, Nickolaus M, Springer J, Doring F, Daniel $\mathrm{H}$, Fischer A. Localization of the peptide transporter PEPT2 in the lung: implications for pulmonary oligopeptide uptake. Am J Pathol 2001; 158: 707-714.

16. Hauser-Kronberger C, Hacker GW, Muss W, Saria A, Albegger K. Autonomic and peptidergic innervation of human nasal mucosa. Acta Otolaryngol 1993; 113: 387-393.

17. Figueroa JM, Mansilla E, Suburo AM. Innervation of nasal turbinate blood vessels in rhinitic and nonrhinitic children. Am J Respir Crit Care Med 1998; 157: 1959-1966.

18. Stevenson DD, Lewis RA. Proposed mechanisms of aspirin sensitivity reactions. J Allergy Clin Immunol 1987; 80: 788-790.

19. Patriarca G, Nucera E, DiRienzo V, Schiavino D, Pellegrino $\mathrm{S}$, Fais G. Nasal provocation test with lysine acetylsalicylate in aspirin-sensitive patients. Ann Allergy 1991; 67: 60-62.

20. Wellbrock M, Mertens J, Cornelius M, Brasch J. Intranasal provocation with lysine acetylsalicylic acid. HNO 1993; 41: 577-581.

21. Bachert C, Wagenmann M. Aspirin intolerance. HNO 1993; 41: 16-17.

22. Bienenstock $\mathrm{J}$, Tomioka $\mathrm{M}$, Stead $\mathrm{R}$, et al. Mast cell involvement in various inflammatory processes. $\mathrm{Am}$ Rev Respir Dis 1987; 135: Suppl. 6, 5-8.
23. Lee TH, Smith CM, Arm JP, Christie PE. Mediator release in aspirin-induced reactions. J Allergy Clin Immunol 1991; 88: 827-829.

24. Bosso JV, Schwartz LB, Stevenson DD. Tryptase and histamine release during aspirin-induced respiratory reactions. J Allergy Clin Immunol 1991; 88: 830-837.

25. Ferreri NR, Howland WC, Stevenson DD, Spiegelberg HL. Release of leukotrienes, prostaglandins, and histamine into nasal secretions of aspirin-sensitive asthmatics during reaction to aspirin. Am Rev Respir Dis 1988; 137: 847-854.

26. Christie PE, Smith C, Arm JP, Lee TH. Aspirin sensitive asthma. Clin Exp Allergy 1992; 22: 171-175.

27. Szczeklik A. The cyclooxygenase theory of aspirin-induced asthma. Eur Respir J 1990; 3: 588-593.

28. Arm JP, O'Hickey SP, Spur BW, Lee TH. Airway responsiveness to histamine and leukotriene E4 in subjects with aspirin-induced asthma. Am Rev Respir Dis 1989; 140: 148-153.

29. Christie PE, Smith CM, Lee TH. The potent and selective sulfidopeptide leukotriene antagonist, SK\&F 104353, inhibits aspirin-induced asthma. Am Rev Respir Dis 1991; 144: 957-958.

30. Kowalski ML, Sliwinska-Kowalska M, Igarashi Y, et al. Nasal secretions in response to acetylsalicylic acid. $J$ Allergy Clin Immunol 1993; 91: 580-598.

31. Picado C, Ramis I, Rosello J, et al. Release of peptide leukotriene into nasal secretions after local instillation of aspirin in aspirin-sensitive asthmatic patients. Am Rev Respir Dis 1992; 145: 65-69.

32. Said SI, Mutt V. Polypeptide with broad biological activity: isolation from small intestine. Science 1970; 169: 1217-1218.

33. Baraniuk JN, Lundgren JD, Okayama M, et al. Vasoactive intestinal peptide in human nasal mucosa. J Clin Invest 1990; 86: $825-831$.

34. Woodhead CJ. Neuropeptides in nasal mucosa. Clin Otolaryngol 1994; 19: 277-286.

35. Said SI. Vasoactive peptides in the lung, with special reference to vasoactive intestinal peptide. Exp Lung Res 1982; 3: 343-348.

36. Widdicombe JG. Autonomic regulation. i-NANC/e-NANC. Am J Respir Crit Care Med 1998; 158: Suppl. 5, 171-175.

37. Maggi CA, Giachetti A, Dey RD, Said SI. Neuropeptides as regulators of airway function: vasoactive intestinal peptide and the tachykinins. Physiol Rev 1995; 75: 277-322.

38. Kurian S. Vasoactive intestinal polypeptide (VIP) in vasomotor rhinitis. IRCS Med Sci 1983; 11: 425-426.

39. Heppt W, Peiser C, Cryer A, et al. Innervation of human nasal mucosa in environmentally triggered hyperreflectoric rhinitis. J Occup Environ Med 2002; 44: 924-929.

40. Fang SY, Shen CL. Neuropeptide innervation and neuroendocrine cells in allergic rhinitis and chronic hypertrophic rhinitis. Clin Exp Allergy 1998; 28: 228-232.

41. Martinez C, Delgado M, Abad C, Gomariz RP, Ganea D, Leceta J. Regulation of VIP production and secretion by murine lymphocytes. J Neuroimmunol 1999; 93: 126-138.

42. Delgado M, Abad C, Martinez C, et al. Vasoactive intestinal peptide in the immune system: potential therapeutic role in inflammatory and autoimmune diseases. J Mol Med 2002; 80: $16-24$.

43. Fang SY, Shen CL, Ohyama M. Distribution and quantity of neuroendocrine markers in allergic rhinitis. Acta Otolaryngol 1998; 118: 398-403.

44. Springer J, Geppetti P, Fischer A, Groneberg DA. Calcitonin gene-related peptide as inflammatory mediator. Pulm Pharmacol Ther 2003; 16: 121-130.

45. Jacoby DB, Costello RM, Fryer AD. Eosinophil recruitment to the airway nerves. J Allergy Clin Immunol 2001; 107 : 211-218 